\title{
The Role of Parental Illness Representations and Parental Coping in the Metabolic Control of Adolescents with Type 1 Diabetes
}

\author{
Almeida $\mathrm{AC}^{1}$, Leandro $\mathrm{E}^{1}$ and Pereira $\mathrm{MG}^{2 *}$ \\ ${ }^{1}$ University of Minho, Institute of Social Sciences, Portugal \\ ${ }^{2}$ University of Minho, School of Psychology, Portugal
}

*Corresponding author: Pereira MG, University of Minho, School of Psychology, Department of Applied Psychology, Address: Campus de Gualtar, 4710-245 Braga, Portugal, E-mail: gracep@psi.uminho.pt

\section{Research Article}

Volume 2 Issue 1

Received Date: February 24, 2017

Published Date: April 04, 2017

\section{Abstract}

Background: Parental illness representations and parental coping influence the adaptation process of adolescents with type 1 diabetes. Thus, the purpose of this study was to study the role of family representations in the metabolic control of adolescents with type 1 diabetes.

Methods: The sample included 100 adolescents with type 1 diabetes and their parents while waiting for a routine endocrinology appointment. Parents answered the Brief-Illness Perception Questionnaire (B-IPQ; Broadbent, Petrie, Main \& Weinman, 2006) and Coping Health Inventory for Parents (McCubbin, McCubbin, Patterson, Cauble, Wilson, \& Warwick, 1983). Glycosylated hemoglobin was assessed before the medical appointment.

Results: Parental coping (understanding medical situation) was negatively correlated with metabolic control, i.e., higher parental coping was associated with better metabolic control. Parental illness representations (consequences, personal control, illness coherence and emotional representation) were positively associated with metabolic control, i.e., more consequences, less personal control, less illness coherence and worse emotional response were related to worse metabolic control. Parental illness representation (emotional response) and parental coping (understanding the medical situation) were predictors of metabolic control, explaining $18.2 \%$ of the variance.

Conclusion: Intervention programs should address parental coping strategies to deal with the complex management of diabetes self-care in the family daily activities and focus on parental representations of diabetes in order to increase metabolic control, and prevent diabetes complications, thus contributing to a better adaptation to type 1 diabetes for both parents and adolescents.

Keywords: Adolescents; Type 1 Diabetes; Parental Illness Representations; Parental Coping and Metabolic Control 


\section{Pediatrics \& Neonatal Biology Open Access}

\section{Introduction}

Type 1 diabetes is one of the most common metabolic diseases of childhood and requires the adherence to a complex and demanding treatment plan, which becomes a parent's responsibility and can interfere with normal family routines [1]. The study of the Diabetes Control and Complications Trial Group [2], had concluded that an intensive monitoring of glycemic levels and multiple insulin injections were needed to prevent diabetes complications and improve metabolic control and quality of life in children and adolescents with type 1 diabetes. This change in parents and adolescents daily routines may contribute to psychological distress and decrease quality of life of both parents and adolescents with type 1 diabetes [3]. The destruction of pancreatic cells that produce insulin by autoimmune factors seems to be the cause of an absolute absence of endogenous insulin, requiring exogenous insulin [4]. In Portugal, the incidence of type 1 diabetes in children under 19 years old was about 11.5 new cases for each 100000 children, the lower result of the recent years [5]. Parents try to promote an optimal development in their type 1 diabetes child and the disease outcomes reflect how diabetes has been under control [6].

Parents also report that the experience of caring for a type 1 diabetes child is overwhelming, requiring constant vigilance and worries about hypoglycemia and hyperglycemia episodes [3-7]. Dealing with the complex diabetes demands and with the well fare of all family members, often creates psychological distress [8], which may influence the metabolic and psychological outcomes of the adolescent with type 1 diabetes [6]. Although a certain level of stress in parents with adolescents with chronic disease, as type 1 diabetes, may be important to maintain the parent's motivation in the diabetes management, as Stallwood [9] found regarding the influence of stress and coping in glycemic control, higher levels of parents stress have been related to good metabolic control. For Cameron and colleagues [10], psychological outcomes of adolescents with type 1 diabetes and their families should be improved in order to foster the adaptation process to a chronic illness. In the study of Grey et al. [7], regarding an intervention program of coping skills training to parents with children with type 1 diabetes, the quality of parental coping influenced the adaptation process to diabetes, for both children and parents. Having the Childhood Adaptation Model for Chronic Disease, as a framework, Whittemore et al. [11] considered parental coping as an important factor that could mediate the adaptation of adolescents with chronic illness, assessed through metabolic control outcomes. Also, gender may influence the child's ability to adapt to illness [11]. As
Skinner, John and Hampson [12] had observed in their study, there are gender differences in metabolic control in adolescents with type 1 diabetes, with female adolescents showing the worse outcomes since they are more concerned with the impact of diabetes on selfimage and weight changes [12]. In addition, the developmental phase of adolescence, with pubertal and psychosocial changes interfere with metabolic control and adolescents' quality of life [4]. In fact, the hormones involved in puberty and the transfer of the responsibility of self-care diabetes management from parents to adolescents, also contribute to a bad metabolic control, in adolescents [13]. Conflicts with parents, feeling different from peers and concerns regarding bad metabolic control negatively influence adolescents' quality of life $[14,15]$. On the other hand, Hoey [16] concluded that positive family factors, such as less conflicts, more family support, well defined responsibility tasks and good quality of life were associated with improvement in metabolic control of adolescents with type 1 diabetes.

The Common-Sense Self-Regulation Model of Leventhal et al. [17], shows how illness representations regarding a threatening experience, such as chronic disease influence the coping strategies. The experience with the illness symptoms, the information shared with health professionals and other parents in identical situations and the experience with the daily living activities may change illness representations [18]. In fact, illness representations influence family support, the development of coping strategies and may condition the adaptation process to a chronic illness, such as type 1 diabetes, in adolescents [12]. In their study about the influence of illness representations, Gaston, Cotrell and Fullen [19] had observed that threatening family representations about diabetes were related to less monitoring of glycemic control by adolescents.

The present study focused on the influence of parental illness representations and parental coping on adolescent's metabolic control. We hypothesized that: parental illness representations and parental coping will be associated and predict metabolic control in adolescents with type 1 diabetes and that parents of female adolescents will present more threatening illness representations.

Knowing the variables that predict metabolic control is important from a heuristic point of view in order to better understand the process of adaptation to type 1 diabetes in adolescents as well as preventing diabetes complications, in the future. 


\section{Pediatrics \& Neonatal Biology Open Access}

\section{Materials and Methods}

\section{Design and Participants}

A convenient sample of 100 adolescents with Type 1 Diabetes and their parents while waiting for a diabetes medical appointment, in two urban central hospitals, in Portugal participated in the study. Using an effect size of .15 , power of .80 and taking into consideration the number of predictors, a sample size of 97 was needed [21].

The inclusion criteria was: age between 12 and 19 years old, being accompanied by a parent, type 1 diabetes duration for at least one year, being in ambulatory care and having no other diagnosed chronic disease, besides type 1 diabetes.

The sample included $52 \%$ of male adolescents. Mean age was 15.12 years old $(S D=1.92)$ and diabetes duration mean was 6.6 years ( $\mathrm{SD}=3.77$ ). All adolescents were high school students. The glycosylated hemoglobin (HbA1c) was 9.1\% (SD=1.6), which represents a high risk for diabetes complications [2,21]. The glycemic control on monitored four or more times a day by $88 \%$ of adolescents and $90 \%$ of the adolescents administered at least 4 insulin injections per day. Also, $78 \%$ of adolescents were accompanied by their mother, $73 \%$ lived in a nuclear family (two-parent family) versus $16 \%$ that lived in single-parent family and $50 \%$ had at least one sibling. Mean age for parents was 44.51 years (SD=5.66),15\% had four years of education, $16 \%$ six years of education, $22 \%$ nine years of education, $25 \%$ twelve years of education and 22\% university education. Of the total sample, $78 \%$ worked in a full time job.

\section{Procedure}

The study was approved by the ethical committee of the two Portuguese hospitals where data collection took place. The adolescents and their parents were invited to participate and all signed an informed consent. Parents and adolescents answered the questionnaires in a quiet room. When the adolescent was accompanied by both parents, only the primary care giver participated in the study. A nurse registered the adolescent's glycosilated hemoglobin results.

\section{Measures}

Adolescents and respective parents participated in this study. Adolescents answered to a sociodemographic and clinical questionnaire. Parents answered to Coping Health Inventory for Parents, of McCubbin et al. [22] and a version of the Brief Illness Perceptions Questionnaire, of Broadbent et al. [23], which assessed the parental illness representations about the type 1 diabetes of the adolescent.

Sociodemographic and Clinical Questionnaire: Each adolescent and parent gave information about their gender, age and grade in school. Parents informed about clinical data of adolescents, such as, diabetes duration, number of glycemic monitoring and number of insulin administrations per day, and about the typology of their family.

Brief-Illness Perception Questionnaire (B-IPQ; Broadbent, Petrie, Main \& Weinman, 2006): The BIPQ assess illness representations in terms of their cognitive and emotional components. This instrument is composed of 9 items that each one is relative to one of the nine dimensions: consequences, timeline, personal control, treatment control, identity, concern, illness coherence, emotional representation and causal representation [23]. The first eight items are rated on a scale from 0 to 10 . Items personal control, treatment control and illness coherence are inversely rated [24]. Higher results indicate more threatening illness perceptions about the adolescent's illness. The Portuguese version was adapted by Figueiras and Alves [25].

Coping Health Inventory for Parents (CHIP, McCubbin, McCubbin, Patterson, Cauble, Wilson, \& Warwick, 1983): The CHIP measures the parents coping with the demands of the care of a child with a chronic disease in the family daily routines. This instrument is composed of 45 items, which are organized into three subscales: Maintaining family integration, cooperation, and an optimistic definition of the situation, Maintaining social support, self-esteem, and psychological stability and Understanding the medical situation through communication with other parents and consultation with medical staff. The Portuguese adapted version [26] are organized in similar components proposed by McCubbin et al. [22]. The internal consistency of each component was $.80, .82$ and .76 for Maintaining Family Integration (16 items), Maintaining Family Support (19 items) and Understanding medical situation (9 items), respectively. Each item is scored in a Likert-type scale ranging from 0 to 3 , where 0 indicates a coping strategy that is considered "not helpful" and 3, a coping strategy that is considered "extremely helpful". High results indicate high levels of parental coping.

Metabolic Control: A nurse measured the glycosylated hemoglobin, in order to assess the metabolic control of each adolescent. The value of the $\mathrm{HbA}_{1 c}$ represents the mean of glycemic levels over the last three months, and according to the DCCT Group [2] had observed, should be lower than $7 \%$ to prevent minor and major complications related to type 1 diabetes. 


\section{Pediatrics \& Neonatal Biology Open Access}

\section{Data Analyses}

A Pearson correlation test was performed to test the associations between clinical, psychological variables and metabolic control. To test differences according to gender $t$ test were conducted and a Manova regarding the CHIP subscales. To test the predictors, a regression model was performed. In the first block, sociodemographic and clinical variables were included (age and diabetes duration) and in the second block, the psychological variables: parental illness representations and parental coping. To control for multi-collinearity, the variance inflation factor value (VIF) was established at below 2 and the tolerance coefficient was set to be greater than .60 .

\section{Results}

\section{Relationship between Parental Illness Representations, Parental Coping and Metabolic Control}

\begin{tabular}{|c|c|c|c|c|}
\hline \multirow{2}{*}{ Variables } & \multicolumn{2}{|c|}{ Mean (State Deviation) } & $\begin{array}{c}\text { Differences on } \\
\text { Adolescent's Gender }\end{array}$ & $\begin{array}{c}\text { Pearson } \\
\text { Correlations }\end{array}$ \\
\cline { 2 - 5 } & $\begin{array}{c}\text { Male } \\
(\mathbf{n = 5 2}\end{array}$ & $\begin{array}{c}\text { Female } \\
(\mathbf{n = 4 8})\end{array}$ & $\boldsymbol{t}$ Test/ MANOVA & $\mathbf{2}$ \\
\hline 1 - Diabetes Duration & $15.10(1.92)$ & $15.15(1.94)$ & $\mathrm{t}(98)=-.946 ; \mathrm{p}>.05$ & -.039 \\
\hline 2 - Metabolic Control & $8.91(1.59)$ & $9.31(1.62)$ & $\mathrm{t}(98)=1.240 ; \mathrm{p}>.05$ & --- \\
\hline $\begin{array}{c}\text { 3 - Parental Illness Representation - } \\
\text { Consequences }\end{array}$ & $5.17(2.79)$ & $6.52(2.84)$ & $\mathrm{t}(98)=2.394 ; \mathrm{p}<.05$ & $.339^{* * *}$ \\
\hline $\begin{array}{c}\text { 4 - Parental Illness Representation - } \\
\text { Timeline }\end{array}$ & $9.23(2.04)$ & $9.29(2.22)$ & $\mathrm{t}(98)=.143 ; \mathrm{p}>.05$ & .055 \\
\hline $\begin{array}{c}\text { 5 - Parental Illness Representation - } \\
\text { Personal Control }\end{array}$ & $2.85(2.48)$ & $3.08(2.35)$ & $\mathrm{t}(98)=.489 ; \mathrm{p}>.05$ & $.273^{* *}$ \\
\hline $\begin{array}{c}\text { 6 - Parental Illness Representation - } \\
\text { Treatment Control }\end{array}$ & $.37(1.03)$ & $.79(1.60)$ & $\mathrm{t}(98)=1.598 ; \mathrm{p}>.05$ & .003 \\
\hline $\begin{array}{c}\text { 7 - Parental Illness Representation - } \\
\text { Identity }\end{array}$ & $5.71(2.15)$ & $5.94(2.54)$ & $\mathrm{t}(98)=.631 ; \mathrm{p}>.05$ & .015 \\
\hline $\begin{array}{c}\text { 8 - Parental Illness Representation - } \\
\text { Concern }\end{array}$ & $6.98(2.40)$ & $7.13(2.47)$ & $\mathrm{t}(98)=.768 ; \mathrm{p}>.05$ & -.150 \\
\hline $\begin{array}{c}\text { 9 - Parental Illness Representation - } \\
\text { Illness Coherence }\end{array}$ & $2.04(2.25)$ & $2.29(2.46)$ & $\mathrm{t}(98)=.538 ; \mathrm{p}>.05$ & $.206^{*}$ \\
\hline $\begin{array}{c}10 \text { - Parental Illness Representation - } \\
\text { Emotional Representation }\end{array}$ & $6.19(2.82)$ & $6.81(2.92)$ & $\mathrm{t}(98)=1.079 ; \mathrm{p}>.05$ & $.345^{* * *}$ \\
\hline $\begin{array}{c}11 \text { - Parental Coping - Maintaining of } \\
\text { Family Integration }\end{array}$ & $44.93(3.05)$ & $44.70(3.28)$ & $\mathrm{F}(98)=.133 ; \mathrm{p}>.05$ & .013 \\
\hline $\begin{array}{c}\text { 12 - Parental Coping - Maintaining of } \\
\text { Family Support }\end{array}$ & $43.46(6.70)$ & $43.08(5.94)$ & $\mathrm{F}(98)=.088 ; \mathrm{p}>.05$ & -.024 \\
\hline $\begin{array}{c}13 \text { - Parental Coping - Understanding } \\
\text { Medical Situation }\end{array}$ & $23.86(3.06)$ & $23.81(2.13)$ & $\mathrm{F}(98)=.009 ; \mathrm{p}>.05$ & $-.232^{*}$ \\
\hline
\end{tabular}

Table 1: Gender Differences and Associations Between Age, Metabolic Control, and Parental Coping in Adolescents

with Type 1 Diabetes.
The results showed that parental coping was negatively associated with metabolic control $(\mathrm{r}=-.232$; $\mathrm{p}<.05)$, i.e., better parental coping was related to better metabolic control (low glycemic hemoglobin values). In turn, parental illness representations regarding consequences ( $\mathrm{r}=.339$; $\mathrm{p}<$. 001), personal control $(\mathrm{r}=$. $273 ; \mathrm{p}<.01)$, illness coherence $(\mathrm{r}=.206 ; \mathrm{p}<.05)$ and emotional representation $(r=.345 ; \mathrm{p}<.001)$ were positively related with metabolic control, i.e., more consequences, less personal control, worse illness coherence and worse emotional response were related to worse metabolic control (Table 1).

\section{Gender Differences}

The results showed significant differences on metabolic control, according to gender on consequences (illness representations), i.e., parents of female adolescents perceived more consequences of type 1 diabetes (Table 1). 


\section{Pediatrics \& Neonatal Biology Open Access}

\section{Predictors of Metabolic Control}

Parental coping (Understanding of the medical situation $)(\beta=-.215 ; \quad p<.05)$ and parental illness representation (emotional representation) $(\beta=.233 ; p<$ .05 ) predicted metabolic control, explaining $18.2 \%$ of

the variance. Thus, higher parental coping was related to better metabolic control and worse family emotional response was associated with worse metabolic control, in adolescents with type 1 diabetes (Table 2).

\begin{tabular}{|c|c|c|c|c|}
\hline \multirow{2}{*}{ Variables } & \multicolumn{3}{|c|}{ Metabolic Control } \\
\cline { 2 - 5 } & $\mathbf{\Delta R}^{\mathbf{2}}$ & $\mathbf{B}($ SD) & $\boldsymbol{\beta}$ & $\boldsymbol{p}$ \\
\hline Gender of Adolescent & .182 & & & \\
\cline { 2 - 5 } & & $-.172(.301)$ & -.054 & $>.05$ \\
\hline Parental Illness Representation - Consequences & & $.086(.064)$ & .154 & $>.05$ \\
\hline Parental Illness Representation - Personal Control & & $.105(.073)$ & .157 & $>.05$ \\
\hline Parental Illness Representation - Illness Coherence & & $-.003(.075)$ & -.004 & $>.05$ \\
\hline Parental Illness Representation - Emotional Representation & & $.131(.061)$ & .233 & $<.05$ \\
\hline Parental Coping - Understanding the Medical Situation & & $-.131(.056)$ & -.215 & $<.05$ \\
\hline
\end{tabular}

Table: 2 Final Linear Multiple Regression for Metabolic Control in Adolescents with Type 1 Diabetes.

\section{Discussion}

This study analyzed how parental coping and parental illness representations influenced metabolic control in adolescents with type 1 diabetes. The first hypothesis about the association between parental coping and parental illness representation with adolescent's metabolic control was confirmed. Thus, the dimension Understanding the Medical Situation of parental coping and parental illness representations of consequences, personal control, illness coherence and emotional response were related to metabolic control. This finding is similar to the conclusions of Stallwood [9] and Grey [6] studies, that also showed that parental coping was related to metabolic control, and as Grey [6] stated, metabolic control and psychological outcomes reflect the efficacy of the parental coping strategies in the management of diabetes demands, in family dailylife routines. On the other hand, Wisting et al. [27] found that adolescent's illness representation, such as, consequences, personal control and concerns were associated with metabolic control and Law [28] found that the perceptions of both adolescents and parents were convergent in all dimensions, except consequences, with parents showing more concern when compared with adolescents. Feelings of guilt and worry about the impact of the chronic disease, such as type 1 diabetes, may explain the differences in parents and adolescents' perceptions [19].

In this study, parents of female adolescents regarding consequences were significantly different from the parents' perception of male adolescents. Literature corroborates this finding. Skinner, John and Hampson [12] found that female adolescents had worse metabolic control than male adolescents, which may influence the perceptions of their parents related to the consequences of the diabetes.
In terms of predictors, parental coping was related to the understanding of medical situation and parental illness representation (emotional representation) predicted metabolic control, explaining about $18 \%$ of the variance. These findings are in accordance with the literature. In fact, Pereira et al. [29], in a study about the influence of family variables in adherence, metabolic control and quality of life of adolescents with type 1 diabetes found similar results. In fact, the dimension of understanding of medical situation of parental coping, also predicted metabolic control. However, Grey et al. [7] did not find a relationship between parental coping and metabolic control, in a group of parents that received coping skill training. However, adolescents were in very good control and therefore, the authors hypothesize that the coping skill training program would be more important to families with children and adolescents with bad metabolic control, because they could develop new strategies to maintain a positive balance between parental coping strategies, family functioning, child/adolescents responsibility for diabetes self-care and metabolic control [7]. Also Stallwood [9] did not find any relationship between parental coping and metabolic control in children with type 1 diabetes, despite higher stress levels in parents that were related to higher glycosylated hemoglobin in children with type 1 diabetes. Either in the study of Pereira et al. [29] or in the Wisting et al. [27], both authors found that illness representations were predictors of metabolic control, in adolescents with diabetes. However, in the study of Pereira et al. [29], the dimensions of timeline and illness coherence predicted metabolic control and in the Wisting et al. [27], the personal control dimension predicted metabolic control. 


\section{Pediatrics \& Neonatal Biology Open Access}

This study has some limitations that need to be acknowledged. The cross-sectional design, the size of the sample and the assessment of parental coping mainly in mothers, that assumed the role of primary caregiver, are the main limitations. Future studies should use a longitudinal design and analyze whether parental illness representations change over time as the adolescent grows older.

The findings of this study highlight the importance of developing interventions in which both parents and adolescents are present to improve their skills to manage diabetes self-care and increase their adaptation to diabetes. Also, since stress can influence parental coping strategies, it is important that parents stress levels be assessed in order to minimize their negative impact on the family adjustment process.

\section{Conclusion}

In the adaptation process of adolescents with type 1 diabetes, parental coping showed an influence on metabolic control. Higher parental coping (understanding of medical situation) is an important issue to take into consideration, particularly in adolescents with poor metabolic control. Parents' emotional response also predicted metabolic control and together with parental representations of diabetes consequences, personal control, and illness coherence were related to metabolic control. The results emphasize the need for intervention programs to focus on illness representations as well as education regarding type 1 diabetes, in parents.

\section{References}

1. Moore SM, Hackworth NJ, Hamilton VE, Northam EP, Cameron FJ (2013) Adolescents with Type 1 Diabetes: parental perceptions of child health and family functioning and their relationship to adolescent metabolic control. Health and Quality of Life Outcomes 11(50): 8.

2. Diabetes Control and Complications Trial (DCCT) Research Group (1993) The effect of intensive treatment of diabetes on the development and progression of long-term complications in insulindependent diabetes mellitus. New England Journal of Medicine 329(14): 977-986.

3. Whittemore R, Jaser S, Chao A, Jang M, Grey M (2012) Psychological Experience of Parents of Children With Type 1 Diabetes: A Systematic MixedStudies Review. The Diabetes Educator 38(4): 562579.
4. Guo J, Whittemore R, He GP (2011) The relationship between diabetes self-management and metabolic control in youth with type 1 diabetes: an integrative review. Journal of Advanced Nursing 67(11): 22942310.

5. SPD (2016) Diabetes: Factos e Números - 0 Ano de 2015 [Diabetes: Facts and Numbers] (Relatório Anual do Observatório Nacional da Diabetes 12/2016). Lisboa: Observatório da Diabetes. Retrieved.

6. Grey M (2000) Coping and Diabetes. Diabetes Spectrum 13(3): 167.

7. Grey M, Jaser SS, Whittemore R, Jeon S, Lindemann E (2011) Coping Skills training for parents of children with type 1 diabetes: 12-month outcomes. Nursing Research and Practice 60(3): 173-181.

8. Tak YR, McCubbin M (2002) Family stress, perceived social support and coping following the diagnosis of a child's congenital heart disease. Journal of Advanced Nursing 39(2): 190-198.

9. Stallwood L (2005) Influence of Caregiver Stress and Coping on Glycemic Control of Young Children with Diabetes. Journal of Pediatric Health Care 19: 293-300.

10. Cameron FJ, Northam EA, Ambler, GR, Dabenam D (2007) Routine Psychological Screening in Youth with Type 1 Diabetes and Their Parents. A notion whose time has come? Diabetes Care 30(10): 27162724 .

11. Whittemore R, Jaser S, Guo J, Grey M (2010) A conceptual model of childhood adaptation to type 1 diabetes. Nursing Outlook 58(5): 242-251.

12. Skinner TC, John M, Hampson SE (2000) Social Support and Personal Models of Diabetes as Predictors of Self-care and Well-Being: a Longitudinal Study of Adolescents with Diabetes. Journal of Pediatric Psychology 25(4): 257-267.

13. Chao A, Whittemore R, Minges KE, Murphy KM, Grey M (2014) Self-Management in Early Adolescence and Differences by Age at Diagnosis and Duration of Type 1 Diabetes. The Diabetes Educator 40(2): 167-177.

14. Grey M, Whittemore R, Jeon S, Murphy K, Faulkner MS, et al. (2013) Internet Psycho-Education Programs Improve Outcomes in Youth With Type 1 Diabetes. Diabetes Care 36(9): 2475-2482. 


\section{Pediatrics \& Neonatal Biology Open Access}

15. Jaser SS, Faulkner MS, Whittemore R, Jeon S, Murphy K, et al. (2012) Coping, Self-Management, and Adaptation in Adolescents with Type 1 Diabetes. Annals of Behavioral Medicine 43(3): 311-319.

16. Hoey H (2009) Psychosocial factors are associated with metabolic control in adolescents: research from the Hvidoere Study Group on Childhood Diabetes. Pediatric Diabetes 10(13): 9-14.

17. Leventhal H, Nerenz DR, Steele DJ (1984) Illness representation and coping with health threats. In A. Baum, Taylor SE, Singer JE (Eds.), Handbook of Psychology and Health (pp. 219-252). Hillsdale, NJ: Lawrence Erlbaum Associates.

18. Figueiras M, Marcelino DS, Claudino A, Cortes MA, Maroco J, et al. (2009) Patients illness schemata of hypertension: the role of beliefs for the choice of treatment. Psychology and Health, 25(4): 507-517.

19. Gaston AM, Cottrell DJ, Fullen T (2012) An examination of how adolescent-caregiver dyad illness representations relate to adolescents' reported diabetes self-management. Child: Care, Health \& Development 38(4): 513-519.

20. Steyerberg EW (2009) Clinical Prediction Models. A Practical Approach to Development, Validation, and Updating. New York: Springer.

21. Rewers MJ, Pillay K, de Beaufort C, Craig ME, Hanas $\mathrm{R}$, et al. (2014) Assessment and monitoring of glycemic control in children and adolescents with diabetes. Pediatric Diabetes 15(20): 102-114.

22. McCubbin H, McCubbin MA, Patterson JM, Cauble AE, Wilson LR, et al. (1983) CHIP - Coping Health Inventory for Parents: An Assessment of Parental Coping Patters in the Care of the Chronically Ill
Child. Journal of marriage and Family 45(2): 359370.

23. Broadbent E, Petrie KJ, Main J, Weinman J (2006) The Brief Illness Perception Questionnaire. J Psychosom Res 60: 631-637.

24. Broadbent E, Wilkes C, Koschwanez H, Weinman J, Norton S, et al. (2015) A systematic review and meta-analysis of the Brief Illness Perception Questionnaire. Psychology \& Health 30(11): 13611385.

25. Figueiras MJ, Alves NC (2007) Lay perceptions of a serious illnesses: An adapted version of the Revised Illness Perceptions Questionaire (IPQ-R) for healthy people. Psychology and Health 22(2): 143-158.

26. Almeida AC, Pereira MG (2016) Psychometric Properties of the Portuguese Version of the Coping Health Inventory for Parents (CHIP) of Adolescents with Chronic Illness. Journal of Pediatric Nursing 31(5): 528-536.

27. Wisting L, Bang L, Natvig H, Skrivarhaug T, DahlJorgensen K, et al. (2016) Metabolic Control and Illness Perceptions in Adolescents with Type 1 Diabetes. Journal of Diabetes Research 16: 1-7.

28. Law U (2002) Dissimilarity in adolescents and maternal representations of Type 1 Diabetes: exploration of relations to adolescent well-being. Child Care Health \& Dev 28(5): 369-378.

29. Pereira MG, Almeida A, Rocha L, Leandro E (2011) Predictors of adherence, metabolic control and quality of life in adolescents with type 1 diabetes. In: Liu CP (Eds.) Type 1 Diabetes- Complications, Pathogenesis, and Alternative Treatments. Rijeka: In Tech pp: 119-140. 